\title{
A EDUCAÇÃO DE JOVENS E ADULTOS: AVANÇOS E DESAFIOS
}

\section{ARTIGO ORIGINAL}

OLIVEIRA, Gilmar Antônio de ${ }^{1}$

OLIVEIRA, Gilmar Antônio de. A Educação de Jovens e Adultos: Avanços e Desafios. Revista Científica Multidisciplinar Núcleo do Conhecimento. Ano 04, Ed. 08, Vol. 03, pp. 126-138. Agosto de 2019. ISSN: 2448-0959, Link de acesso: https://www.nucleodoconhecimento.com.br/educacao/avancos-e-desafios

\section{RESUMO}

Este artigo teve como propósito abordar, e levar em consideração a importância da Educação de Jovens e Adultos através de seus avanços e desafio, tendo por objetivo abordar a relevância do mesmo para a educação. É propósito deste estudo, analisar a sua evolução durante os últimos anos, através dos métodos bibliográficos e explorativo. Ademais analisar se está sendo aplicada nas escolas. Sem dúvida esse segmento da educação ficou bastante tempo sem a atenção dos governantes, após muitos anos de evolução e conquistas fica notório a sua implantação na educação em forma de lei. Assegurando que o jovem maior de 15 anos e adultos com mais de 60, voltem aos estudos e almeje um futuro promissor através da educação. Tornando-se pessoa críticas e participativas na sociedade.

Palavras chaves: Educação, cidadãos, participativo, sociedade.

\section{INTRODUÇÃO}

Várias tentativas vêm sendo feitas por toda história do Brasil, para cessar o analfabetismo, especialmente, o analfabetismo dos jovens e adultos. Por tornar-se um

1 Doutorando em Ciências da Educação, Mestre em Ciências da Educação, Especialista em Psicopedagogia e Gestão Escolar, Graduado em Licenciatura em Matemática e Pedagogia. 
problema de ordem estrutural, todas as iniciativas até a conjuntura atual lograram pouco êxito, pois, no Brasil, conforme dados do IBGE/INEP (2017), em números absolutos, a taxa de analfabetos representa 11,5 milhões de pessoas que não escrevem e nem leem.

A incidência chega a ser quase três vezes maior na faixa da população acima de 60 anos, $19,3 \%$, muito além que o dobro entre pretos e pardos $(9,3 \%)$ em relação aos brancos (4,0\%) (IBGE/INEP, 2017).

Esse é o cenário da situação educacional do Brasil atualmente, que aponta para a carência de implementação e execução de mais Políticas Educacionais e, é neste contexto que o Programa de Educação de Jovens e Adultos (EJA), se propõe a atender um público alvo que não conseguiu acompanhar o ensino de forma regular, estando fora da idade prevista, seja por carência de vagas nas instituições públicas, ou por privação de recursos financeiros através da família, sem um norte de incluí-los em nossa sociedade, para capacitar à escrita e leitura, cooperando para a inclusão dos educandos no universo do trabalho.

Todavia, assistimos perplexa uma desvalorização por parte do governo atual em prestigiar a Educação, de modo geral, e isso é muito grave, trazendo consequências devastadoras para o país, no contexto mundial.

O sistema de ensino no Brasil através de sua história tem passado por um método de transição, buscando novas alternativas pedagógicas que possam extinguir o analfabetismo no país, através de programas que sirvam de incentivo para os jovens e adultos buscarem o saber formal.

Mesmo assim, percebemos que a desistência escolar através da implantação dos programas tem apresentado resultados negativos, tornando-se desafiador para o professor, manter o aluno permanecendo na escola. Não se trata de alfabetizar um mundo no qual a leitura era privilégio de poucos letrados, mas sim, em formar o ser humano, mediante os contextos nos quais estão inseridos. 
Foi no governo Vargas dado início as primeiras iniciativas de combate ao analfabetismo, acelerando o metodo de campanhas de educação voltadas a adolescentes e adultos analfabetos do país.

O presidente Getúlio Vargas tinha uma compreensão mais abundante na questão educacional, ainda que as suas propostas estivessem voltadas para o futuro, ele considerava que os problemas da educação se relacionavam com melhoramento dos transportes e das estradas.

Com isso, fez o Estado reconhecer e assumir a obrigação de construir escolas para todos, transformando, assim, a educação em uma obrigação do Estado e um direito de cada cidadão, pelo menos até o ensino médio. Estas, portanto, foram as primeiras providências de cunho governamental com o propósito de extinguir o iletrado no Brasil.

\section{EDUCAÇÃO DE JOVENS E ADULTOS: AVANÇOS E DESAFIOS}

A Educação de Jovens e Adultos - EJA tem por intenção proporcionar a educação fundamental aos que não tiveram condições de se educar através de escola na faixa etária determinada nas Diretrizes Curriculares propostas e na Lei no 9.394/96, Lei de Diretrizes e Bases da Educação (LDB).

A idade mínima para frequentar a EJA é 15 anos para o Ensino Fundamental e 18 anos para o Ensino Médio, isto previsto na LDB.

No Art. 22 da LDB no 9.394/96 nos diz que:

Está prevista a Educação de Jovens e Adultos - EJA, classificada como parte integrante da Educação Básica, sendo, portanto, dever do Estado disponibilizar vagas nessa modalidade de ensino aos que não foram escolarizados na idade considerada como correta. Antes, porém, é necessário analisar, mesmo que de forma breve, a história da Educação de Jovens e Adultos (LDB no 9.394/96).

Diante o exposto, fica notória através dessa lei a obrigatoriedade dos governantes em implantar e disponibilizar a execução da EJA, para atender essa camada de pessoas 
desprovidas de estudos. Nesse sentido em concordância a LDB, faremos um relato a respeito da história da Educação de jovens e Adultos em sequência.

\subsection{CONTEXTO HISTÓRICO DA EJA}

A EJA é necessariamente considerada como componente integrante através da história da educação em nosso país, sendo uma das arenas importantes, onde se empreendem esforços para a democratização do acesso ao ensino, desde o período de 1940, embora haja menção já na pouco duradoura Constituição Federal de 1934.

Em um breve retrospecto, vemos diferentes campanhas que visavam extinguir o analfabetismo, como a criação do (FNEP) Fundo Nacional de Ensino Primário em 1942, do Serviço de Educação de Adultos e da Campanha de Educação de Adultos, ambos em 1947, da Campanha de Educação Rural iniciada em 1952 e da Campanha Nacional de Erradicação do Analfabetismo em 1958.

Nos tempos da ditadura militar, entre as décadas de 1960 e 1970, havia o Movimento Brasileiro de Alfabetização (MOBRAL), foi um projeto do governo criado pela Lei $n^{\circ}$ 5.379 , de 15 de dezembro de 1967, e que propunha a alfabetização funcional a jovens e adultos, visando: "conduzir a pessoa humana a adquirir técnicas de leitura, escrita e cálculo como meio de integrá-la a sua comunidade, permitindo melhores condições de vida".

Idealizado no regime militar, os adultos e jovens, frequentaram as aulas do Movimento Brasileiro de Alfabetização (MOBRAL), que dispunha como propósito ofertar letramento e alfabetização às pessoas que se encontravam fora da idade escolar convencional. Entretanto, a crise econômica dos anos 80 tornou inviável a continuação desse movimento em benefício da alfabetização, ao passar a ser administrado pela Fundação Educar.

Depois, no decorrer da redemocratização, foram criados os cursos supletivos. No governo de Fernando Henrique Cardoso, foi intitulado o Programa Alfabetização 
Solidária e no governo de Luiz Inácio Lula da Silva, o Programa Brasil Alfabetizado (PBA).

Todas essas políticas colaboraram, em maior ou menor escala, em diminuir o percentual de analfabetismo, o qual vem aos poucos baixando. Todavia, nenhuma dessas políticas foi suficiente para cessar o analfabetismo. Desse modo, chegamos à segunda década do século 21 com a vergonhosa marca de mais de 11 milhões de analfabetos.

Para os estudiosos na área, a única maneira de melhorar os indicadores é respeitar as especificidades desses alunos, pessoas que não concluíram, ou pelo menos começou o ensino básico. Entre as dificuldades analisadas, estão: o currículo, muitas vezes adaptados dos conteúdos da escola regular; a formação inapropriada dos docentes; a prática de convocar voluntários para exercer o ensino nesse processo de alfabetizar; e a polêmica acerca da idade para matricular-se na EJA, que atualmente é de 15 anos.

Segundo Saltini (2008, p.29):

A educação abre caminhos e tornando-se gente, o indivíduo qualifica-se como um ser social pronto para contribuir para o seu país e também para a sociedade. Um ser livre que busca, critica, renova, entende, pensa e possui estrutura necessária para integrar-se à sua família e ao seu Estado. Enfim ele é um ser que se relaciona em cooperação e desafios principalmente em competições.

A Educação de Jovens e Adultos - EJA é uma modalidade que dispõe como propósito assegurar o direito à educação para os que não dispuseram no momento oportuno aos estudos na idade devida. Assim sendo, os indivíduos com diferentes idades, raça, gênero e cultura.

A EJA também alcança os alunos considerados de terceira idade, sendo eles, os que já têm 60 anos. A escola para os idosos é de extrema importância, tanto é assim que os percentuais de frequência escolar são maiores na terceira idade. À volta aos estudos para eles representa o aumento da autoestima, de satisfação, de integração social, entre outros. 
Em concordância com os direitos fundamentais da pessoa humana, previsto na Constituição Federal de 1988 em seu artigo 5oe é assegurado a todos estudar tanto em escola particular quanto oficial, sem discriminação de qualquer espécie; portanto o direito do idoso à educação faz jus diante das legislações, bem como no seu estatuto que diz em seu dispositivo legal que:

Art. 21. O Poder Público criará oportunidades de acesso do idoso à educação, adequando currículos, metodologias e material didático aos programas educacionais a ele destinados.

Portanto, o EJA, que se destina ao ensino de jovens e pessoa adultas, alcança aqueles cuja idade é 60 anos ou mais que isso. Trata-se de um programa governamental da maior relevância destinado ao ensino dos jovens e adultos fora da idade escolar.

\section{A EVOLUÇÃO DA EDUCAÇÃO DE JOVENS E ADULTOS}

É importante conhecer o procedimento de evolução da EJA no nosso país, entretanto, os anais nos demonstram as diversas reformulações desta forma de ensino, preliminarmente definida "para o trabalhador", a qual continua em execução, não diferente como diversas outras modalidades da educação.

A datar da colonização portuguesa, foi que teve início a inquietação para a escolarização de pessoas adultas no Brasil. Através de ação dos padres jesuítas com intuito de alfabetizar e catequizar os povos indígenas. Proporcionavam aos colonizadores uma dominação territorial e a utilização do serviço local, com a consequente aculturação dos povos nativos.

Pilletti (1988) nos diz que:

A realeza e a igreja aliavam-se na conquista do Novo Mundo, para alcançarem de forma mais eficiente seus objetivos: a realeza procurava facilitar o trabalho missionário da igreja, na medida em que esta procurava converter os índios aos costumes da Coroa Portuguesa (PILLETTI, 1988, P.165). 
Os jesuítas usavam a pregação da fé católica e o oficio educativo. Através do trabalho missionário, tentavam "salvar almas", abrindo acesso à penetração dos colonizadores.

O Brasil quando colônia, a educação indígena dos adultos tornou-se insignificante. A dominação das técnicas, de escrita e leitura não se fez primordial para os integrantes da sociedade colonial, visto que se respaldavam essencialmente em exportar matéria prima. Entretanto, não se preocupavam em ampliar a educação em todos os níveis sociais.

Em 1988 quando acontece à vinda da família real ao Brasil, houve mudanças referente ao cenário da educação brasileira. Tornou-se precisa a composição de um sistema educacional da aristocracia portuguesa, os quais tinham como objetivo organizar equipes para ocuparem novos cargos técnicos e burocráticos.

Diante o exposto surge então à primeira escola noturna em 1854 a partir de 1876 já podemos contar com 117 escolas em todo o território brasileiro, como nas províncias do Pará e do Maranhão, os quais já possuíam escolas de educação formal.

Com a vinda da industrialização e urbanização, após a primeira Guerra Mundial originou-se uma nova burguesia urbana e fragmentos emergentes de uma burguesia pequena reivindicavam o acesso à educação, segmento esse os quais aspiravam por uma educação acadêmica e elitista, enquanto o restante das pessoas permanecia analfabeta e inferiorizada.

Com a Revolução de 1930, surgiram mudanças políticas e econômicas no país, transcorreu um expressivo aumento da urbanização e industrialização, e passou a exigir uma escolarização maior da população, principalmente em se tratando de adolescentes e adultos, os quais não eram agraciados em políticas públicas, políticas essas que não the deram oportunidades de acesso à escola no tempo devido.

A educação no Brasil foi citada na Constituição Federal de 1934, no Cap. II, art.150, onde tratava da educação e da cultura. Através deste documento a união fixou um Plano Nacional de Educação, baseado num formato para abranger os graus e níveis 
de ensino fundamental e gratuito, com obrigatoriedade da frequência, inclusive dos adultos.

A partir dos anos 40 surgiram diversas ações políticas e pedagógicas, a exemplo: 0 Fundo Nacional de Ensino Primário- FNEP; o INEP- Instituto Nacional de Estudos e Pesquisas Educacionais Anísio Teixeira, estimulando e realizando estudos na área; como também o surgimento de ações direcionado ao ensino supletivo; aparece também a CEAA - Campanha de Educação de Adolescentes, estudo esse que se preocupou com a preparação do material didático para essa clientela.

Em 1947 a Organização das Nações Unidas para a Educação, a Ciência e a Cultura (UNESCO), solicito um Plano de Campanha de Educação de Adolescentes e Adultos o qual foi aprovado. Campanha essa elaborada por Lourenço Filho, um educador angustiado com o social, teve sua participação frente ao movimento provocado por mobilização em benefício para educação de Jovens e Adultos no País.

Tivemos o I congresso Nacional de Educação de Adultos, e do Seminário Interamericano de Educação de Adultos, ambos na década de 1940, nortearam importantes referências para a EJA. Veio então o II Congresso Nacional de Educação de Adultos que marcou grandes acontecimentos na área, nesse contexto surgi a presença de Paulo Freire que, liderou uma pequena classe de educadores do Estado de Pernambuco, onde propunha e defendia a educação para adultos incentivando a decisão, a colaboração, a ação e a incumbência política e social.

O preceito de Paulo Freire começa ser estruturado no decênio de 1960, especificamente em 1962. Esse pensamento parte de uma interpretação crítica do mundo , fornecido através da teórica-metodológica em uma concepção autêntica, onde propõe que a alfabetização de adultos deve surgir com base onde o educando está inserido numa realidade em que vive, e que possa participar de sua transformação.

Segundo Freire (1996) em suas palavras afirma que: 
Ensinar exige respeito aos "saberes dos educandos" de forma que educadores e escolas devam não somente respeitar os saberes trazidos pelas classes populares, os quais foram construídos socialmente na prática comunitária, mas também buscar o estabelecimento das razões de ser destes saberes com os conteúdos pela escola trabalhados (FREIRE, 1996, p.33)

O Movimento Brasileiro de Alfabetização (MOBRAL) teve início em anos de 1970, onde seu principal objetivo era a estruturação do ser humano. Com a Ditadura Militar (1964 a 1985). Surgiu nesse período histórico, uma educação direcionada para formar pessoas qualificada.

No decorrer do Governo Militar na década de 1970 foi implantada, a primeira Lei de Diretrizes e Bases da Educação (LDB), Lei № 5692/71. Lei essa tendo por objetivo organizar da educação de adultos através do ensino supletivo, com pretensões de escolarizar uma parte significativa da população possível a custos baixos, para atender às reivindicações de atividades de trabalho do período.

A EJA volta a ter avanços importantes só na Constituição de 1988, onde o artigo 208 da constituição federal garante que "a Educação passa a ser direito de todos, independentemente de idade, e nas disposições transitórias" surgindo então metas e recursos orçamentários para que o analfabetismo volte a ser erradicado.

Em 2002 o Governo Federal volta a lembrar da EJA, enfatizando que passa a ser responsabilidade dos estados e municípios, e não contempla o programa com os recursos federais, já que o FUNDEF (Fundo de Manutenção e Desenvolvimento do Ensino Fundamental e de Valorização do Magistério) era atribuído ao Ensino Fundamental, causando desconsideração a essa especificidade de ensino oriunda pela escassez de investimentos acessível.

Após a Lei de Diretrizes e Bases da Educação Nacional-LDBEN o 9394/96 ser aprovada, decretou-se uma referência a cerca da EJA no Título III, artigos 4 e 5, perfazendo assim ganho bastante significativo para a educação dos adultos, reconhecendo esse modo de ensino. 
A EJA voltou a ter prioridade para o Governo Federal em 2003, com metas para erradicar o analfabetismo, o Ministério da Educação lançou o Programa Brasil Alfabetizado (PBA) que proporciona a jovens e adultas oportunidades de continuar seus estudos, em um período curto de tempo.

De acordo com Brasil (2005):

O Brasil Alfabetizado é desenvolvido em todo o território nacional, com o atendimento prioritário a municípios que apresentam alta taxa de analfabetismo, sendo que $90 \%$ destes localizam-se na região Nordeste. Esses municípios recebem apoio técnico na implementação das ações do programa, visando garantir a continuidade dos estudos aos alfabetizandos. Podem aderir ao programa por meio das resoluções específicas publicadas no Diário Oficial da União, estados, municípios e o Distrito Federal (BRASIL.2005, p. 23).

Enfatizamos que o PBA se pronuncia como um mecanismo de fortalecimento da educação, considerada como entrada de impulsão para elevação, individual, social e coletiva, dos educandos num País onde as desigualdades socioeconômicas são empecilhos ao acesso de bens culturais e materiais para a sociedade.

Em referência a sua avaliação, entendemos que o programa citado tem estudado a implementar para os processos de avaliação e o acompanhamento das propostas pedagógicas com as quais mantém parceiras, contribuindo dessa maneira para haja a consolidação da educação.

Os governantes conforme dito anteriormente, são obrigados a subsidiar recursos e apoio a continuidade dos estudos dessa população, em parceria com outros órgãos governamentais.

\subsection{POLÍTICA E EDUCAÇÃO}

A educação em nosso País decorre por um sistema de ampliação quando nos referimos à oferta de vagas no entorno do ensino. Em contrapartida, com relação à EJA temos que lidar com o abandono dos alunos, durante o período do curso nessa especificidade de ensino. 
Os alunos frequentadores da escola noturna são, em grande quantidade, trabalhadores que, devido várias circunstâncias vivenciadas no cotidiano, exemplificando, encontram dificuldade para ajustar horário do trabalho e os estudos, motivação decorrente advinda dos conteúdos curriculares, e a própria escola que não considera suas práticas e experiências de vida, dentre outras, que acabam por levar o estudante a infrequência ou abandono de seus estudos.

Santos (2003) faz o seguinte comentário:

Os alunos de EJA possuem no trabalho e na família a centralidade de suas vidas. Por este motivo, necessitam arcar com os custos objetivos e subjetivos bem altos e que por vezes implicam na permanência ou não nos estudos (SANTOS, 2003, p. 11-38).

Alunos da EJA em sua totalidade são trabalhadores, a maioria das vezes iniciou o trabalho cedo, obrigado a abandonarem os estudos, outros tinham que cuidar de irmãos menores para que seus pais trabalhassem, além de atividades que os impossibilitam de estudar. Sendo comum, em alguns locais eles realizarem várias atividades par aumentar a renda familiar: distribuir panfletos em sinais, fazer entregas, cuidar de crianças, lavar carros, trabalhar de ajudante na construção civil, entre tantas outras.

Muitos motivos levam os jovens e adultos a ficarem de fora do método de escolarização, entre eles estão: impedimento de aprendizagem, problemas familiares, a não escolarização dos pais, motivos que influenciam o seu comprometimento e permanência na ação educativa.

Em suas palavras Arroyo (2006) nos diz, e serve como reflexão sobre essa situação:

[...] os jovens e adultos continuam vistos na ótica das carências escolares: não tiveram acesso, na infância e na adolescência, ao ensino fundamental, ou dele foram excluídas ou dele se evadiram; logo propiciemos uma segunda oportunidade. (ARROYO, 2006, p.23).

Enquanto educadores, precisamos perceber nossos alunos da EJA como sujeitos necessitados de educação no seu mais amplo sentido, vinculando as instruções que demanda a atual sociedade, para que consigam ser cidadão de direitos e de fato. 
Os estudos desses alunos foram atingidos pelo insucesso ou fracasso escolar, acabando por tornarem-se inseguros, apresentando autoestima baixa. Nesse contexto, seja qual for qual for a decepção, por minúscula que for, leva-o novamente a desistir de seus estudos.

É notório, então, que o problema dessa evasão ultrapasse questões familiares e escolares, visto que a estrutura política e econômica corrente no Brasil afaste do método de escolarização um número considerável de alunos oriundos da população de classes inferiores.

Enfatizamos o pensamento de Freire revelando a educação como forma para conscientizar situação de opressão do grupo de trabalhador, desse modo tornando possível alteração na mudanças I estruturada sociedade. Freire (1996) nos mostra "que a educação não pode ser concebida sem uma tomada de posição política por educandos e educadores".

As decisões políticas continuam negando aos educandos a possibilidade de possuírem uma educação libertadora, que possam transformar o indivíduo e o meio que ele está inserido.

Em sua história a educação está inserida como apolítica, preservando uma partição entre conscientização e conhecimento, devido estarmos inseridos em uma sociedade de classes, na qual as dominantes continuamente conduzem o processo educativo. Pontuamos que a educação no Brasil, por longo período, ficou a mercê das elites, onde sua primeira preocupação era manter seu status quo, tomando para si a escolha de que as classes populares deveriam ser escolarizadas.

A educação, segundo Paulo Freire "é um ato político e se a educação sempre ignorou a política, a política nunca ignorou a educação, e sempre procurou utilizá-la para manutenção de seus interesses". Diante o contexto, a incumbência do especialista da educação com a sociedade deve ser capaz de refletir e agir. Então podemos considerar a educação como princípio de transformação da sociedade.

Freire (2000) em sua análise destaca que: 
A educação passa a ter sentido ao ser humano porque o seu existir se caracteriza como possibilidade histórica de mudanças. Somos ou nos tornamos educáveis porque, ao lado da constatação de experiências negadoras da liberdade, verificamos também ser possível a luta pela liberdade e pela autonomia contra a opressão e o arbítrio (FREIRE, 2000, p. 121)

O pensamento de Paulo Freire é bastante pertinente ao relatar a educação como modo de mudança social, visando sempre à libertação, a transformação da realidade, que possa permitir aos indivíduos uma ampla visão crítica da realidade, precisando, que a aprendizagem seja expressiva, para que o aprendizado da escrita e da leitura oportunize os educandos a se tornarem partes de sua própria história. Desse modo destacamos o ato de conhecer.

Freire (2000), em sua fala quando diz:

O próprio fato de tê-lo reconhecido como tal me obrigou a assumir em face dele uma atitude crítica e não ingênua. Essa atitude crítica, em si própria, implica na penetração na "intimidade" mesma do tema, no sentido de desvelá-lo mais e mais. Assim, [...] ao ser a resposta que procuro dar ao desafio, se torna outro desafio a seus possíveis leitores. É que minha atitude crítica em face do tema me engaja num ato de conhecimento (FREIRE, 2000, p. 86).

Segundo Freire (1996, p.112) "o núcleo fundamental onde se sustenta o processo de educação seria o inacabamento ou a inconclusão do homem". Em acordo com Freire, o indivíduo se percebe inacabado e por isso procura se educar.

No pensamento freiriano, o educador deve guiar o aluno a fazer leitura do seu ambiente histórico e social, seu universo, suas memórias e sua vida integral, tendo dois elementos básicos nesse processo: diálogo e conscientização.

\section{CONSIDERAÇÕES FINAIS}

A luta para combater e erradicar o analfabetismo no País, em comparação com alguns países notadamente de primeiro mundo, teve início muito tardiamente. Pode-se até afirmar que começou em meados de 1934, ou um pouco antes, foi mencionada na Constituição Federal de 1934. De lá até aos dias atuais, muitas mobilizações da 
sociedade com os governos foram esboçadas com a intenção de acabar como analfabetismo, sem que, entretanto, isso se tornasse realidade plenamente.

Podemos citar algumas tentativas do governo benefício da erradicação do analfabetismo no Brasil: o Serviço de Educação de Adultos e a Campanha de Educação de Adultos, ambos em 1947; Campanha de Educação Rural que ocorreu em 1952; a Campanha Nacional de Erradicação do Analfabetismo em 1958; o Movimento Brasileiro de Alfabetização (MOBRAL), em 1967, e que propunha a alfabetização funcional de jovens e adultos, oportunizando conduzir o indivíduo adquirir técnicas de leitura e escrita para integrá-lo comunidade, uma melhor condição de vida ao concluir os estudos.

Posteriormente, no governo de Fernando Henrique Cardoso, foi estruturado o Programa Alfabetização Solidária e no governo de Luiz Inácio Lula da Silva, o Brasil Alfabetizado. Entretanto, temos índices preocupantes de analfabetismo atualmente: segundo o IBGE (2017) a taxa de analfabetos representa 11,5 milhões de pessoas que não sabem ainda escrever e tão pouco lerem. $A$ incidência chega a ser quase três vezes maior na faixa da população de 60 anos ou mais, 19,3\%, e mais que o dobro entre pretos e pardos (9,3\%) em relação aos brancos (4,0\%) (IBGE/INEP, 2017), como já ditos antes.

Apesar de tudo, a luta continua e podemos contar com a EJA - Educação de Jovens e Adultos, cuja faixa etária prevista pela LDB - Lei de Diretrizes e Bases da Educação (Lei no 9.394/96), é de 15 anos para o Ensino Fundamental e 18 anos para o Ensino Médio. A EJA se configura como um projeto de combate ao analfabetismo por excelência, devendo ser prestigiado e nunca negligenciado pelo governo. Este programa alcança também as pessoas da terceira idade, aqueles que já têm mais de 60 anos.

\section{REFERÊNCIAS}

ARROYO, M. Educação de Jovens e Adultos: um campo de direitos e de responsabilidade pública. In: GIOVANETTI, Maria Amélia, GOMES, Nilma Lino e 
SOARES, Leôncio (Orgs). Diálogos na Educação de Jovens e Adultos. Belo Horizonte, MG: Autêntica, 2006.

BRASIL, CONSELHO NACIONAL DE EDUCAÇÃO. (2005). Parecer CNE/CP n.ำ, de 13 de dezembro de 2005. Diretrizes Curriculares Nacionais para o Curso de Pedagogia. Brasília. Disponível em: <http://portal.mec.gov.br/cne/arquivos/pdf/>. Acesso em: 02 fev. 2019.

FREIRE, Paulo. Pedagogia da Autonomia: saberes necessários à prática educativa .26ed. São Paulo: Paz e Terra,1996.

Pedagogia da Autonomia. $31^{\circ}$ ed. RJ: Paz e Terra, 2000.

IBGE/INEP. Analfabetismo no Brasil. Disponível em:<http://www.portal.inep.gov.br>. Acesso em: 30 jan. 2019.

PILETTI, N. Psicologia Educacional. São Paulo: Ática, 1988.

SALTINI, CLÁUDIO. Afetividade e inteligência. Rio de Janeiro: Wak, 2008.

SANTOS, G. L. Quando adultos voltam para a escola: o delicado equilíbrio para obter êxito na tentativa de elevação da escolaridade. In: SOARES, Leôncio (Org.). Aprendendo com a diferença - estudos e pesquisas em educação de jovens e adultos. Belo Horizonte, MG: Autêntica, 2003.

Enviado: Julho, 2019.

Aprovado: Agosto, 2019. 